\title{
Estrofas en vascuence al Dos de Mayo y poesía en el mismo idioma sobre la Guerra de la Independencia
}

En la Biblioteca Nacional de París se conserva un manuscrito con el siguiente título: "Les Français à Madrid, en 1808". Contiene una composición en vascuence, de doce estrofas, relativa a los acontecimientos de la capital de España el Dos de Mayo de dicho año.

Francisque Michel, en su obra Le Pays Basque (1857) ofrece la primera estrofa de esta composición.

Jalen Vinson, en su libro Le folk-lore du Pays Basque (Paris, 1883) inserta la traducción al francés de las doce estrofas.

Resurreción María Azcue, en su Cancionero popular vasco, número 628, nos presenta la décima estrofa, junto con otra nueva, y la melodía para cantarla, tal como las recogió en Muguerre, Laburdi, de labios de un tal Casenave.

El semanario Herria, de Bayona, con fecha 14 de diciembre de 1961, reproduce ocho estrofas, la $1,2,3,4,5,6,810$ y 7 , en ese orden y con notables variantes.

Lino Akesolo, en su artículo "Bertsolaritza Pernando Amezketarraren garaian" (El bersolarismo en tiempo de Fernando de Amézqueta) (Revista Egan, 1969) incluye la segunda estrofa de esta composición.

Jesús María Leizaola, en sus obras 1808-1814 en la Poesía Popular Vasca y Crónicas y romances en la poesía euskérica ofrece las doce estrofas, con alguna variante.

Estas son las fuentes donde hemos encontrado esta composición. Nosotros nos basaremos para este trabajo en el texto de la Biblioteca Nacional de París.

Dicen así:

$$
\begin{aligned}
& \text { Mila zortzi ebun eta zortzigarrenian } \\
& \text { soldado sartu ginen, oì! enozentzian; } \\
& \text { zerbitzatu behar ginuela Printziaren guardian; } \\
& \text { egin ere badugu beRartu girenian. }
\end{aligned}
$$

(En 1808, nos alistamos soldados, jay!, inocentemente. Nos dijeron que debíamos servir en la Guardia del Príncipe. Lo hemos hecho cuando ha sido preciso.) 
Qué guardia pudiera ser ésta lo aclara la nota que incluye al final el manuscrito de la Biblioteca Nacional de París:

Pendant ses séjours à Bayonne, Murat s'était formé une garde d' honneur de trois cents Basques: ce batuillon, dont le costume rouge était façonné dans la forme nationale, se composait de l'élite du pays; il donna des preuves d'intrepidité dans plusieurs rencontres et notamment à la prise de Madrid: peu de ces jeunes gens revirent leurs foyers.

L'auteur du récit qui précède faisait partie de cette garde d' honneur.

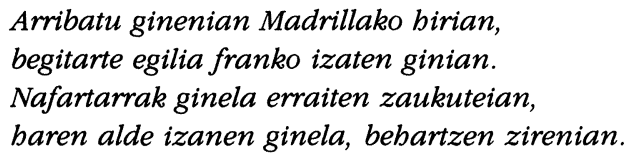

(Cuando llegamos a la ciudad de Madrid, teníamos muchos mirones. Nos decían que éramos navarros y que nos pondríamos de su parte cuando llegara el caso.)

Eso sería lo que los madrileños pensaban cuando se enteraban de que en aquella Guardia había navarros. Quiere decir que no sabían que, además de la Alta Navarra, existía la Baja Navarra, perteneciente a Francia; y que el alzamiento del Dos de Mayo iba preparándose poco a poco.

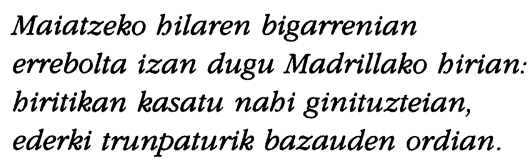

(El Dos de Mayo ha estallado una revuelta en la ciudad de Madrid. Nos han querido expulsar de ella. Pero estaban bien engañados.)

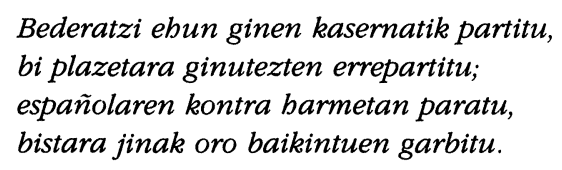

(Salimos novecientos [hombres] del cuartel. Nos distribuyeron en dos plazas, puestos en armas contra los españoles. Hemos liquidado a todo el que se dejaba ver.)

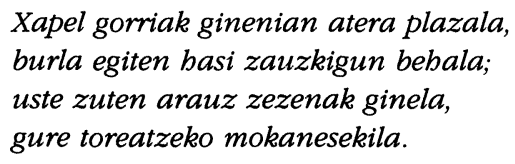

(Cuando salimos a la plaza con nuestras boinas rojas, comenzaron en seguida a hacernos burla. Creían que éramos toros, para torearnos con los pañuelos.) 


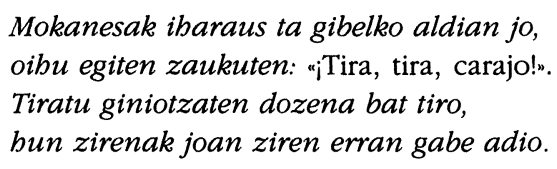

(Agitaban sus pañuelos y nos pegaban en la parte trasera. Nos gritaban: "Tira, tira, carajo!". [Pero] cuando les disparamos una docena de tiros, los que quedaron ilesos se fueron sin decir adiós.)

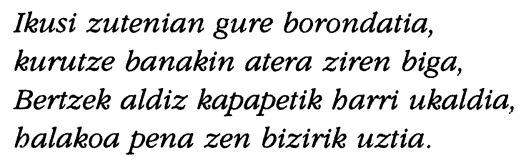

(Cuando vieron nuestra disposición, dos individuos salieron con sendas cruces. Los otros, en cambio, nos lanzaban piedras por debajo de sus capas. Era una pena dejar vivos a los tales.)

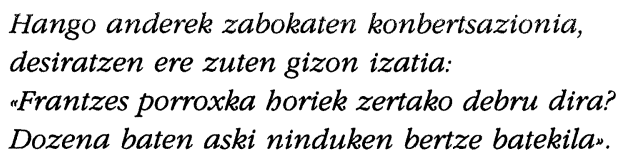

(La conversación que se traían las mujeres [era] que deseaban ser hombres. "¿Para qué diablos sirven estos esmirriados franceses? Acompañada de alguien me atrevía contra una docenan.) La palabra porroxka, que he traducido por esmirriados, no se emplea al sur del Bidasoa y tampoco creo que sea muy usual al norte de dicho río. En el Dictionaire basque-français de Pierre Lhande se le asignan estos significados: ramassis de restes sans valeur, feuilles sèches, ronces menues, tranches de pain avec lesquelles on fait la soupe, miette, petit morceau, morceau de pain que l'on donne aux pauvres. La palabra castellana que abarcara todos esos significados podría ser la de rebuses, muy empleada todavía en Navarra y Aragón.

Esta desgraciada imagen que al parecer produjeron los soldados franceses a las mujeres madrileñas concuerda con lo que nos dice Vicente Palacio Atard en su libro La España del siglo XIX, 1808-1898 (Madrid: Espasa-Calpe,1981).

Todo el vistoso aparato de que se revistió la entrada de los franceses en Madrid el 23 de marzo no pudo evitar, sin embargo, que los españoles se percataran sorprendidos de que los soldados franceses, a quienes se había supuesto marciales y aguerridos, eran en realidad jóvenes bisoños, mal vestidos y poco disciplinados. ¿Influyó en el Dos de Mayo la pobre impresión que causaron en el ánimo popular estas tropas poco escogidas que Napoleón había creído suficientes para dominar España?. 
Fierik basi ziren bere etxetarik, pixtola tiroka bere galerietarik. Gero sinetsi zuten, ongi progaturik, eia frantzes porroxkek bazutenez indarrik.

(Comenzaron valientemente desde sus casas, con tiros de pistola desde los balcones. Luego averiguaron, habiéndolo experimentado bien, si los esmirriados franceses tenían fuerza.)

\author{
Hango anderek egin dute irabazi eder bat: \\ eltziak eta pixerrak aurtiki karriketarat; \\ lur baxera egiliaren bori ezta malur bat: \\ lebengo bigen prezioan erosten dute orai bat.
}

(Las mujeres de allí han hecho un buen negocio: han arrojado a la calle cazuelas y jarros. No es una desgracia para los alfareros; al precio de dos se les compra ahora uno.)

\title{
Frantziako teilla egiler dautzuet goraintzi, orai erna zaitezte nabi baduezie irabazi: Madrillen irabaz bide oral bada segurki, etxeko teillak ere zauzkie aurtiki.
}

(Tejeros de Francia, yo os saludo. Espabilaros ahora si queréis hacer negocio. No hay duda de que en Madrid se pueden conseguir ahora buenas ganancias, [ya que] han arrojado las tejas de las casas.)

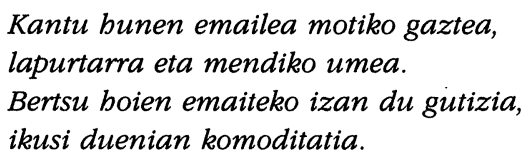

(El autor de estas estrofas es un muchacho joven, labortano y criado en la montaña. Ha tenido el capricho de componer estas estrofas, cuando se le ha ofrecido ocasión para ello.)

No son las únicas estrofas en vascuence que aquella contienda produjo y se han conservado. Las hay también del bando español. Con las que hemos recopilado, pudimos completar dos tomos de la colección Auspoa, con el título Frantzesteko bertsoak (Estrofas de la Francesada).

Casi todas las estrofas de que disponemos son fragmentos de composiciones más largas. Pero algunas de éstas nos han llegado íntegras. 
Por ejemplo, la dedicada a Harispe, un general de Napoleón natural de Baigorri, en la Baja Navarra.

Está también la carta que un soldado vasco-francés escribe en verso desde España a su casa, desesperando de regresar a Francia: "Bizi gareno ez dugu guk ikusiren Frantzia.

Don Manuel Lecuona recogió en Azcoitia una composición de nueve estrofas que describe la vida de los guerrilleros. Hay cuatro estrofas que relatan la batalla de Vitoria, de 21 de junio de 1813. Una composición de catorce, procedente del archivo de Loyola, Azpeitia, da una visión global de toda la guerra.

El donostiarra José Vicente de Echagaray (1773-1853) describió en doce estrofas la quema y saqueo de San Sebastián por los ingleses y portugueses, aliados de España, el día 31 de agosto de 1813; incendio del que sin duda alguna fue testigo ocular.

Martín de Bidarte, de la comarca francesa de Labordi, se lamenta de las calamidades que las tropas de uno y otro bando causan a la población civil, cuando la irrupción de los españoles y sus aliados en Francia, en setiembre de 1813 .

Tenemos también la exhortación a la resistencia a los invasores, por parte de un poeta vasco-francés, no perteneciente al pueblo llano.

Constituyen un canto a la victoria las estrofas cantadas en la iglesia de San Vicente de Abando, de Bilbao, el 30 de mayo de 1814; así como las que se cantaron en la iglesia de Santiago, hoy catedral, de la misma villa, en la Nochebuena de ese año.

Dos largas composiciones nos narran las peripecias de la estatua de plata de San Ignacio perteneciente al altar mayor de la basílica de Loyola, buscada ansiosamente por los franceses y salvada gracias a su traslado a Cádiz, donde se le rindieron honores de capitán general.

Hay también una composición en que la juventud de San Sebastián felicita a Irún por la Real Orden de 28 de julio de 1817, en que Fernando VII concede a la ciudad fronteriza los títulos de Benemérita y Generosa, por el comportamiento de su población durante la segunda batalla de San Marcial, de 31 de agosto de 1813.

Quedan además, como ya he dicho, las estrofas sueltas y bastante numerosas que han llegado a nosotros, y que podemos considerar como restos o fragmentos de otras más o menos largas composiciones.

Debemos agregar, por último, las diecisiete melodías con que se cantaron una u otra de estas composiciones y que han podido ser recogidas de labios del pueblo.

De todo este conjunto se deduce que aquella guerra fue profusamente tratada por la poesía popular vasca, hasta el punto de constituir en su totalidad un gran poema o una historia en verso bastante completa. 
En la antigüedad fueron tema de cantares las luchas entre los banderizos oñacinos y gamboínos de la Baja Edad Media, según se desprende de los fragmentos que han llegado hasta nosotros.

Después viene un vacío de tres siglos, en que seguramente se ensalzaron las hazañas de los marinos y capitanes vascos, en cantares que, por desgracia, no se han conservado.

$\mathrm{Al}$ cabo del tiempo, sobreviene casi de golpe el estimable número de estrofas relativas a la guerra de la Independencia (1808-1814). Se deberá, sin duda, a que esta contienda produjo una conmoción más honda que ninguna de las anteriores en el País Vasco, tanto al norte como al sur del Bidasoa, y en todas sus capas sociales.

Volverá a repetirse el fenómeno en las siguientes guerras que afecten al País Vasco, que serán abundantemente cantadas: primera guerra carlista (1833-1839); primera de África (1859-1860); carlista de 1872-1876; guerra de Cuba (1895-1898); guerra europea del 14, sobre todo en el País Vascofrancés; y la de África de los años 20.

Curiosamente, la guerra civil de 1936 es más escasa en poesía popular. Se debe a que la función de ésta había sido reemplazada por la prensa y la radio.

Pero de entre todos estos conflictos bélicos, quien se lleva con mucho la palma en cuanto al número y calidad de sus cantares es la guerra carlista de 1872-1876, cuya producción poética pretendo publicar en breve.

ANTONIO ZAVALA 